\title{
SVM and RVM Fault Model for Wind Energy Conversion Systm
}

\author{
Rekha S.N., P.Aruna Jeyanthy, D. Devaraj
}

\begin{abstract}
The paper present the fault identification technique for wind Energy conversion system based on SVM (support vector machines) and RVM. A Relevance Vector Machine based fault detection technique and support vector machine fault detection technique with the Benchmark Model of the WECS is carried out with Multi class classification... The proposed implementation would carry out simulation which would consider multiple faults occurring simultaneously with a comparison study of both techniques can be achieved. The algorithm is carried out and the results are found to be satisfactory. The results in MATLAB shows that effective memory usage of each technique.
\end{abstract}

Keywords: Relevance Vector Machine, Support vector machine, Wind Fault Benchmark Model, Wind Generation Fault Diagnosis.

\section{INTRODUCTION}

The innovation of wind power is progressively full grown as of late and wind turbine is additionally improvement towards huge power and too enormous power [1]. The length of the blade and the activity stature of wind turbine become longer and higher as per the expanding limit of wind turbine. Which indicates the blades are increasingly presented to harms during the operation and at the same time it is necessary to monitor the health of generators and converters. The regular strategies outwardly investigate blade's fault highlight, for example, lightning consuming and vibration splitting [2]. Long inspection cycles are the major defects of these methods.[3] The existing generator fault and converter fault are also very expensive.[4].

In wind energy conversion system, location and detection of faults have a significant role, as the shortcomings in the framework would expand the maintenance cost and consequently increment absolute cost wind control. For wind fault identification a bench mark model is developed [5]. This developed model is based on a 4.8MW WECS to detect the fault in the system.

The fault recognition is completed with SVM and for the precision, preparing and tuning times the result is compared with the result obtained by ANN.[6]. The comparison shows that the performance of SVM is better than ANN. Sound and vibration in the tower analysed by empirical mode

Revised Manuscript Received on December 05, 2019.

* Correspondence Author

*Rekha S. N. *, Electrical and Electronics Engg, Sapthagiri college of Engineering, Bangalore, India. sn_rekha@rediffmail.com

P.Aruna Jeyanthy, Electrical and Electronics Engg, Kalasalingam Academy of Research and Education,TamilNadu,India p.arunajeyanthy@klu.ac.in

D.Devaraj, Electrical and Electronics Engg, Kalasalingam Academy of Research and Education,TamilNadu,India d.devaraj@klu.ac.in

decomposition technique is utilized to detect issue in wind generator bearing [7]. To detect the fault in individual wind turbine in nine turbine-based wind farms is really a challenge [5]. In [8] the identification of fault with noise is found by a state estimation membership approach.

In [9] a multi objective optimization model with $H / H$ observer is developed to identify the fault in the sensor and actuator. In the area of application of fault detection the SVM is an efficient technique in machine learning [10],[11],[12] and with this techniques many fault detections are done [13].

In this paper, a comparison study for fault diagnosis method based on SVM and RVM are done for diagnosing different fault in wind energy conversion systems. By using SVM and RVM as fault classifiers, which only need a limited sample information and reaches a efficient diagnosis result [14],[15],[16].The present work actualizes the SVM and RVM on the benchmark model for finding multiple faults occurring simultaneously on the bench mark model developed by Odgaard et al [5].

\section{BENChMARK Model OF WECS With FAults}

The present implementation is carried out by using the benchmark model developed in [5]. It includes all the parts model in WECS. The vector $v_{w}$ denotes the input to the turbine which represents the different sequences of wind The wind and pitch model combined with aerodynamic model is represents blade and pitch model. The wind turbine aerodynamics is modelled in terms of blades torque (1)

$$
{ }_{r}(t)=\frac{R^{3} C_{q}((t) .(t)) v_{w}(t)^{2}}{2}
$$

represent the Air density, $R$ represents the radius of rotor, $C_{q}, \quad$ is the coefficient of torque and tip speed ratio respectively, is the pitch angle.

The torque equation of each blade is defined by (2)

$$
\begin{aligned}
& { }_{w}(t)={ }_{1 i 3} \frac{R^{3} C_{q}\left((t) ._{i}(t)\right) v_{w}(t)^{2}}{6} \ldots \ldots \ldots \ldots \ldots . . . \\
& \frac{\beta(s)}{\beta_{c}(s)}=\frac{\omega_{n}^{2}}{s^{2}+2 \varsigma \omega_{n} s+\omega_{n}^{2}} \ldots \ldots \ldots \ldots \ldots \ldots \ldots(3)
\end{aligned}
$$


Damping factor, natural frequency $n$ defines the second order transfer function of the hydraulic pitch system as shown in equation (3). The same transfer function is adopted for all three blades, If undisturbed the pitch system would remain the same. While any abnormal condition occurs in the pitch system a drop in hydraulic power would be evident along with the air pressure increase. The drop in power is affected by the parameters as defined as $\omega_{n 2}$ and $\varsigma_{2}$, air pressure parameters is $\omega_{n 3}$ and $\varsigma_{3}$. The sensed pitch value correction is calculated by finding the difference of the reference sensor value to the mean of the sensor values thus obtained. It is depicted as in (4).

$\beta_{r_{i}, f_{i}^{i}}[n]=\beta_{r_{i, j}}[n]-\frac{\Delta \beta_{i, m \mathbb{1}}[n]+\Delta \beta_{i, m 2}[n]}{2}$.

Drive train model is that which would transfer the torque generated from the rotor to the generator. The drive train model as defined in (5) and (6) and represents the model of the gear box that ensures the variation of the speed from lower to higher speed.

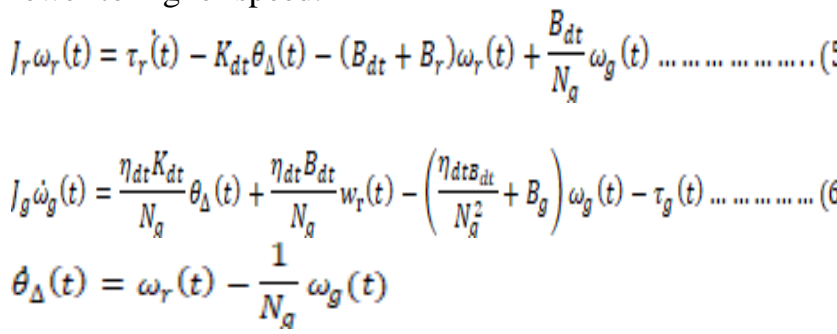

The low speed shaft moment of inertia is represented by $l_{r}$ and the drive train torsion

stiffness is represented $K_{d t}$, drive train torsion damping coefficient is represented $B_{d t^{x}}$

high speed shaft viscous friction is $B_{q}$. Gear ratio is $N_{q}$, high speed shaft moment of inertia is $l_{a}$,the drive train efficiency is $\eta_{d t}$. Drive train torsion angle is $\theta_{\Delta}(t)$. $\eta_{d t}$ would be denoted as $\eta_{d t z}$ when fault occurs in drive train.. The representation of electrical model is as defined in (7).

$\frac{\tau_{g}(s)}{\tau_{g, I}(s)}=\frac{\alpha_{g e}}{s+\alpha_{g e}} \ldots \ldots \ldots(7)$

Where $\sigma_{q e}$ represents the control parameters of the electrical model. The generator power is characterized by the following equation (8)

$P_{q}(t)=\eta_{q} \omega_{q}(t) \tau_{q}(t)$

The efficiency of the generator defined as $\eta_{g}$. While wind speed is more than the nominal speed a power optimization is considered. If there is less power generated then controller starts effect. Equation (9) is denoting the variation of power.

$$
P_{q}[n] \geq P_{\gamma}[n] \vee \omega_{q}[n] \geq \omega_{n o m}
$$

Where ${ }^{\omega_{\text {nom }}}$ is the normal speed of generator .

$\omega_{q}[n] \leq \omega_{n o m}-\omega_{\Delta}$
The offset value $\omega_{\Delta}$ which makes to avoid the frequents changes between mode 2 and mode 1 . For the implementation purpose fault condition and variation of mode along with the parameters of the model is taken from [5].

\section{IMPLEMENTATION OF FAULT DETECTION BASED ON SVM}

The technique SVM depends on basic structural risk and statistical hypothesis, which can well take care of the issues of small samples, high measurements and non-linearity, yet uses restricted sample data and is another strategy. The SVM is predominantly contemplate linearly separable problems in pattern recognition. Suppose there is a hyperplane H: $\mathrm{w} . \mathrm{x}+\mathrm{b}$ $=0$, which can correctly separate the samples. At the same time there are two hyperplanes, both parallel to $\mathrm{H}$, suppose $\mathrm{H} 1$ and $\mathrm{H} 2$ :

$\mathrm{w} \cdot \mathrm{x}+\mathrm{b}=-1$

$$
\mathrm{w} \cdot \mathrm{x}+\mathrm{b}=1
$$

Fig 1 shows the optimal hyper plane which SVM needs to get through training. Two different samples in the figure are circles and squares. Each circle and squares speaks to a sample direct relating toward space. The algorithm is scanned for hyper plane $\mathrm{H}$ and its course vertical to typical normal vector. $\mathrm{H} 1$ and $\mathrm{H} 2$ both parallel to $\mathrm{H}$ and cross the sample points hyperplane that is closest $\mathrm{H}$. classified distance is the distance between them. The closest examples to H's plane simply fall on $\mathrm{H} 1$ and $\mathrm{H} 2$. The help vectors are the examples which fall on $\mathrm{H} 1$ and $\mathrm{H} 2$. The typical vector of hyper plane is $\mathrm{w}$ and the segmentation threshold is defined by $b$. All the preparation samples are situated outside of $\mathrm{H} 1$ and $\mathrm{H} 2$ and the accompanying imperatives are fulfilled.

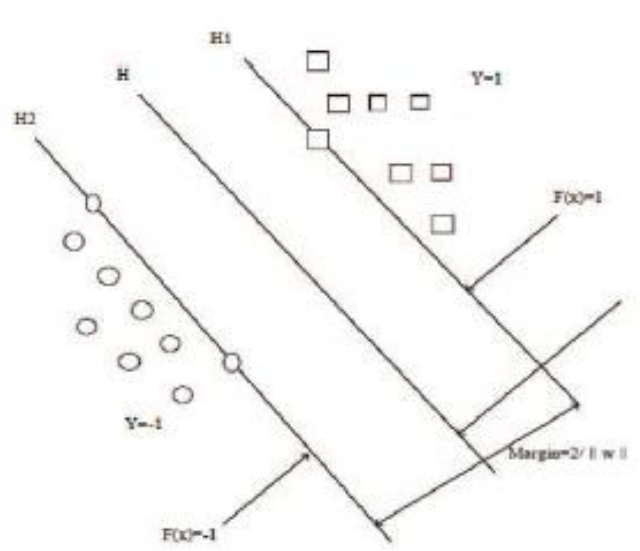

Figure 1. Optimal hyperplane of SVM

$\mathrm{w} \cdot \mathrm{xi}+\mathrm{b} \geq 1(\mathrm{yi}=1)$

$\mathrm{w} \cdot \mathrm{xi}+\mathrm{b} \leq-1$ yi $(=-1)$

As appeared by figure 2 , five stages are required for issue identification is subjected to SVM . The signal received from the machinery operation is extracted and analysed to take 
the decision depends on SVM pattern recognition.

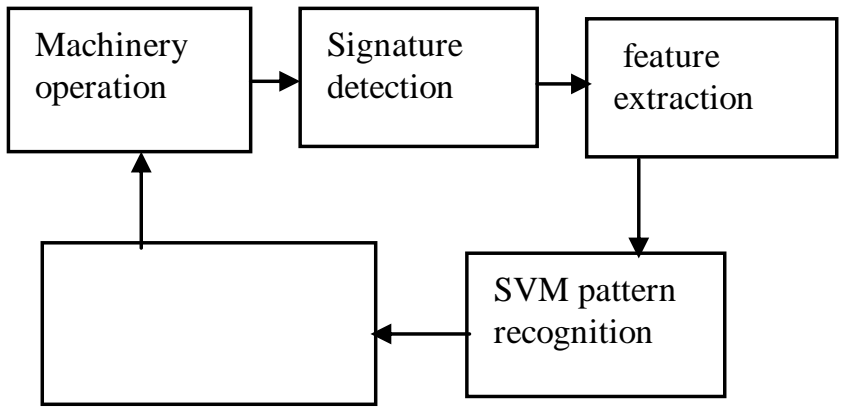

Fig,2 SVM pattern recognition

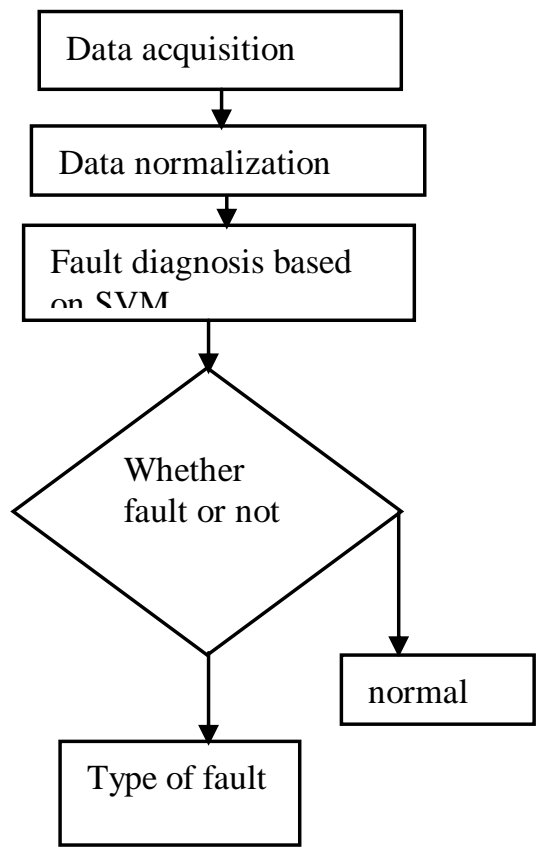

Fig.3 SVM based Implementation of Fault Detection

Fig. 3 represent the general flow chart of SVM based fault diagnosis to be followed to detect different fault in WECS. In this paper mathematical model of wind energy conversion system is used to create various fault model Training loop for SVM

\begin{tabular}{|l|l|l|}
\hline $\begin{array}{l}\text { Mathematical } \\
\text { model of WECS }\end{array}$ & $\begin{array}{l}\text { Measuring parameters of } \\
\text { speed sensors, actuators, } \\
\text { blade pitch sensors }\end{array}$ \\
\hline $\begin{array}{l}\text { SVM structure } \\
\text { after training }\end{array}$ & SVM training \\
\hline
\end{tabular}



Fig 4 training and testing block of SVM

\section{IMPLEMENTATION OF FAULT DETECTION BASED ON RVM}

Assortment of fault stipulations are set up on the RVM and a multi classification structure is made so as to check the fault issue stipulations that are seen in [5].

The numerous RVM structures are created as talked about in [15]. The defective issue situations are mentioned in the Table 1 are presented for preparing and testing RVM:

Training loop of RVM

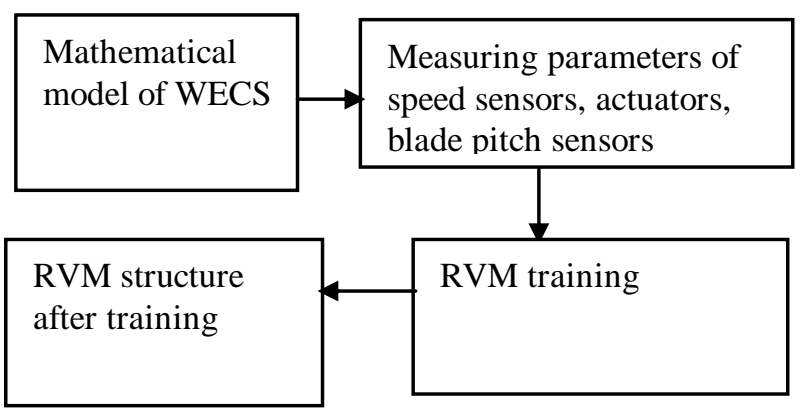

Testing loop of RVM

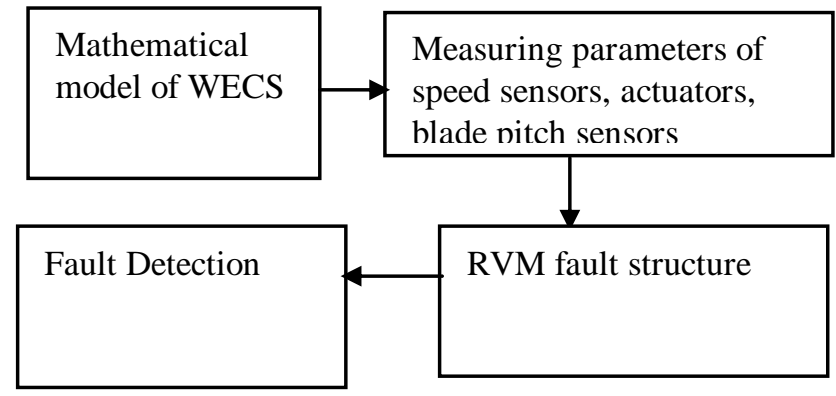

Fig.5 Training and testing block of RVM

The various conditions for faults are trained on the RVM and SVM. The above-mentioned structures are created and studied in detail about the performance of each structure 
The various fault scenarios are stated in the Table 1 is for preparing both the RVM, SVM for identifying fault.

\begin{tabular}{|c|c|c|c|}
\hline $\begin{array}{l}\text { Fault } \\
\text { No. }\end{array}$ & Fault Type & Fault Site & Symbols \\
\hline $1 \mathrm{a}$ & $\begin{array}{l}\text { Fixed } \\
\text { Value }\end{array}$ & \multirow[t]{2}{*}{$\begin{array}{l}\text { Blade Positions } \\
\text { Sensor Faults }\end{array}$} & \multirow{2}{*}{$\begin{array}{c}\Delta \beta_{1, m \mathbb{1}_{\mathrm{n}}} \Delta \beta_{\mathrm{inm} 2} \\
\Delta \beta_{2, m \mathbb{1}}, \Delta \beta \\
\Delta \beta_{2, m \mathbb{1}}, \Delta \beta_{2, m 2}\end{array}$} \\
\hline $1 b$ & $\begin{array}{l}\text { Gain } \\
\text { Factor }\end{array}$ & & \\
\hline $2 \mathrm{a}$ & $\begin{array}{l}\text { Fixed } \\
\text { Value }\end{array}$ & \multirow[t]{2}{*}{$\begin{array}{l}\text { Rotor } \quad \text { Speed } \\
\text { Sensor Fault }\end{array}$} & \multirow[t]{2}{*}{$\Delta \omega_{r_{2} m 1} \Delta \omega_{r_{3} m 2}$} \\
\hline $2 \mathrm{~b}$ & $\begin{array}{l}\text { Gain } \\
\text { Factor }\end{array}$ & & \\
\hline $3 a$ & $\begin{array}{l}\text { Fixed } \\
\text { Value }\end{array}$ & \multirow{2}{*}{$\begin{array}{l}\text { Generator } \\
\text { Speed } \\
\text { Sensor Fault }\end{array}$} & \multirow[t]{2}{*}{$\Delta \omega_{g, m 1} \Delta \omega_{g, m 2}$} \\
\hline $3 b$ & $\begin{array}{l}\text { Gain } \\
\text { Factor }\end{array}$ & & \\
\hline $4 a$ & Offset & $\begin{array}{l}\text { converter system } \\
\text { Actuator Fault }\end{array}$ & $\Delta \tau_{q}$ \\
\hline $5 a$ & $\begin{array}{l}\text { Abrupt } \\
\text { Changed } \\
\text { Dynamics }\end{array}$ & \multirow[t]{2}{*}{$\begin{array}{l}\text { Actuator Fault } \\
\text { Pitch Systems }\end{array}$} & \multirow[t]{2}{*}{$\Delta \beta_{1} \Delta \beta_{2,} \Delta \beta_{a}$} \\
\hline $5 b$ & $\begin{array}{l}\text { Slow } \\
\text { Changed } \\
\text { Dynamics }\end{array}$ & & \\
\hline
\end{tabular}

Table-1 different fault condition

The vector that mirrors the abnormal situation of blade positions is as given in the accompanying equation for training structure.

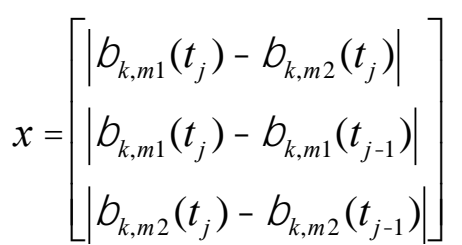

where $\mathrm{k}=1,2,3$ which is the meaning blade number and $\mathrm{i}=1,2$ signifies the mode where in the WECS is working. The $t_{j}$ and $t_{j 1}$ are the time moment at $\mathrm{j}$ and $\mathrm{j}-1$ individually. The absolute estimation $\left|{ }_{k, m 1}\left(t_{j}\right) \quad{ }_{k, m 2}\left(t_{j}\right)\right|$ would change somewhere in the range of .001 and 2, however, so as to separate the abnormal and the ordinary situation the worth is predefined as 5000 .

The fault conditions are characterized in table $\omega_{q, m i}, \omega_{q m i}$ utilized for preparing RVM. The matrix for preparing is given by the accompanying,



While measuring the Gaussian variance is extended to 15 to get the accuracy of measuring. For faults $4 \mathrm{a}$ and 6 the vector is as defined in the following

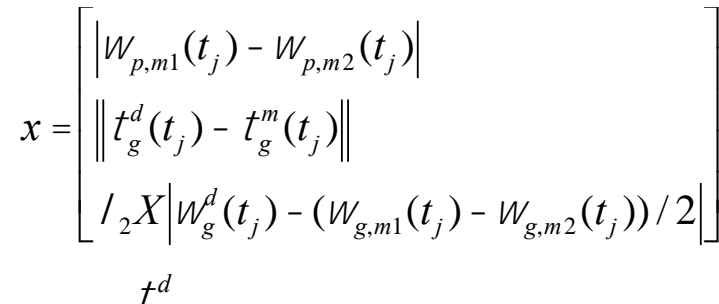

where $\quad g$ is the desired generator torque given by the $\frac{P_{r}}{d}$

controller( $\stackrel{g}{g}$ where $P_{r}$ is the power which is desired to be produced). The factor $2=10{ }^{6} X{ }_{\text {wind }}^{6}$ is the $3^{\text {rd }}$ component of $\mathrm{x}$ in order to utilize the wind speed and for normalization.

\section{OUTCOMES OF THE IMPLEMENTATIONS}

The execution of the work completed, and the outcomes are shown in the accompanying exchange. The $3^{\text {rd }}$ fault situation as talked about in [5] is connected for the usage. By giving the diverse wind speed, which is arbitrarily produced, the variety of speed the torque waveform created as Fig.5.

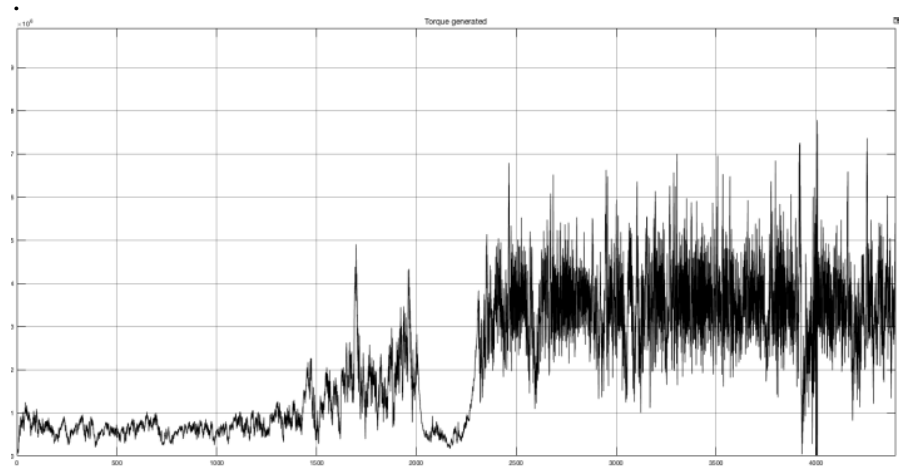

Figure 5. Wind turbine Torque Waveform

The time taken for simulation is 4400 secs. The faults are applied at different places like the below with respect to RVM and SVM.

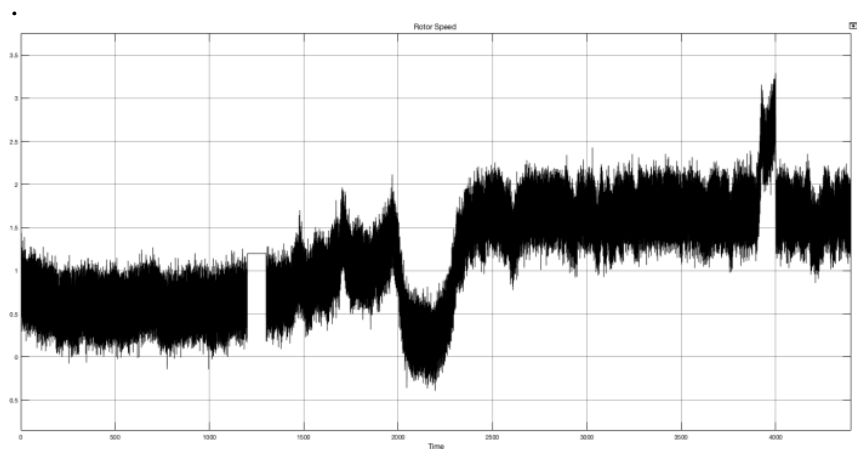

Figure 6. Speed in Wind measured by sensor 1 kept constant between 1200-1300s

The fault detection is obtained by the trained fault model developed by RVM with the above faults

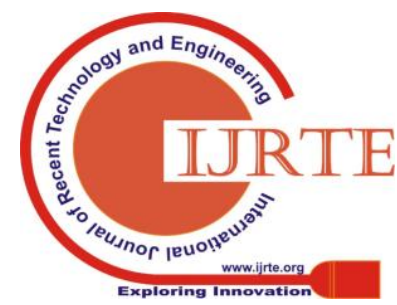






Figure 7 . Speed in Wind measured by sensor 2 kept constant between 1200-1300s

1 in the detection graph shows fault detection and zero in the detection graph when there is no fault.

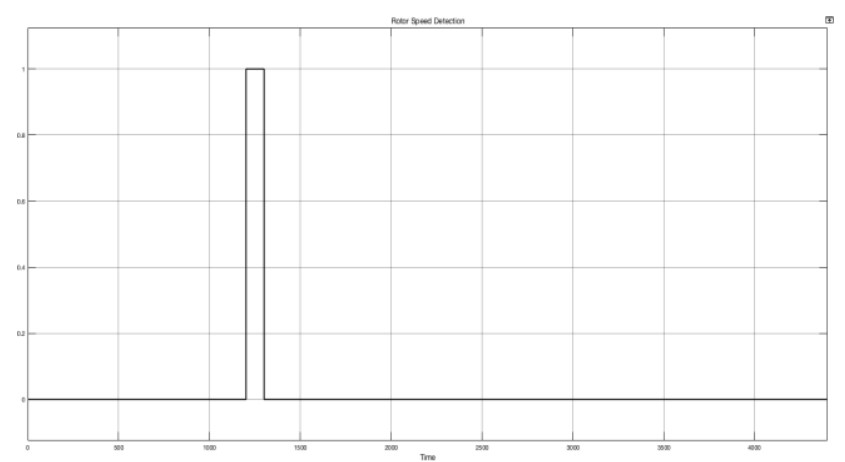

Figure 8. fault detected in sensor 1

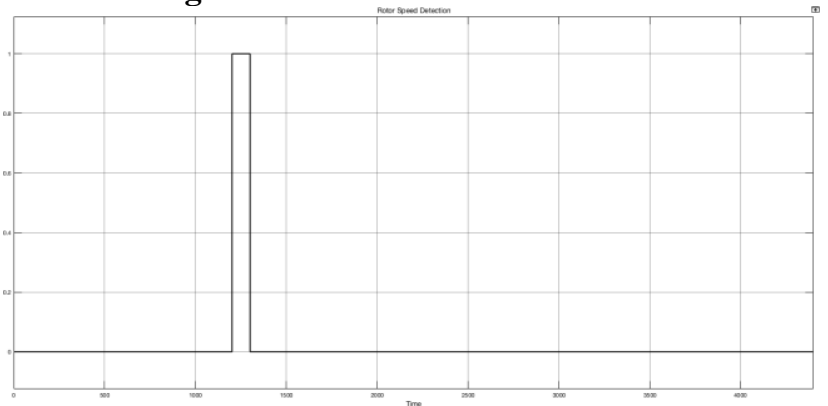

Figure 9. fault detected in sensor 2

Figure 8, 9 displays the rotor speed fault identified in sensor 1 and sensor 2 in 1200-1300s simultaneously. The result obtained by SVM also same. Representation of graph for both SVM and RVM are same the major difference is in the training period the learning of RVM is better compare to SVM.

All the faults that were trained and were detected in the similar way.

\section{CONCLuSIONS}

The RVM and SVM implementation were carried out with the benchmark model developed as mentioned [5]. The RVM and SVM function were trained and final structures created for various fault model and the results were found to be satisfactory. The major contribution of this work is to identify the fault with both RVM and SVM. The performance of RVM is better compared to SVM in learning period. Since the RVM is considering the probability of occurrence of fault the kernel function is fewer compared to SVM . Rapid prototype hardware in loop simulation can be done as a future work

\section{REFERENCES}

1. Global Wind Energy Council. Golbal Wind 2014 Report. 2015-04

2. Qingjun Zhao, Hailong Yao, Li Li, Peng Zhang. Factor Affecting the

3. Service Life of Wind Turbine Blades. Wind Energy Industry. 2011(3):30- 32.

4. Yingqun Xiao, Lianggui Feng. A novel linear ridgelet network approach PCA as preprocessors. Measurement, 2012, Vol.45 (3), pp.297-310.

5. Santos, P, Villa, L.F, Reñones, A.,Bustillo, A, Maudes, J,“An SVM-Based Solution for Fault Detection in Wind Turbines", Sensors 2015, 15, 5627-5648.

6. Odgaard, P.F., Stoustrup, J., and Kinnaert, M. "Fault tolerant control of wind turbines- a benchmark model",IEEE Transactions on Control Systems Technology Vol: 21, No.4, July 2013, 1168 - 1182J. Clerk Maxwell, A Treatise on Electricity and Magnetism, 3rd ed., vol. 2. Oxford: Clarendon, 1892, pp.68-73.

7. Muhammad Rafi, Mohammad Shahid Shaikh,"A comparison of SVM and RVM for Document Classification", ICoCSIM 2012, Medan Indonesia

8. Mollasalehi, E, Wood, D, Sun, Q.“Indicative Fault Diagnosis of Wind Turbine Generator Bearings Using Tower Sound and Vibration", Energies 2017, 10, 1853.

9. Anders BechBorcehrsen, JesperAbildgaardLarsen, JakobStoustrup,'Fault Detection and Load Distribution for the Wind Farm Challenge", IFAC Proceedings Volumes, Volume 47, Issue 3, 2014, Pages 4316-4321

10. SeyedMojtabaTabatabaeipour and Peter F. Odgaard, and Thomas Bak "Fault detection of a benchmark wind turbine using interval analysis", American Control Conference Fairmont Queen Elizabeth, Montréal, Canada June 27-June 29, 2012

11. Xiukun Weiand LihuaLiu"Fault detection of large scale wind turbine systems", International Conference on Computer Science and Education (ICCSE), 2010 IEEE

12. Najim Aldin Mohsun,"Broken rotor bar fault classification for induction motor based on support vector machine-SVM", Engineering\& MIS (ICEMIS), 2017 International Conference on, February 2018

13. Qian Zhao et al,"Damage detection of wind turbine blade based on wavelet analysis",Image and Signal Processing (CISP), 2015 8th International Congress on 14-16 Oct. 2015 ,IEEE

14. Mohanty, Soumya R., et al. "Comparative study of advanced signal processing techniques for islanding detection in a hybrid distributed generation system." IEEE Transactions on Sustainable Energy 6.1 (2015): 122-131.

15. Thayananthan A., Navaratnam R., Stenger B., Torr P.H.S., Cipolla R. (2006) Multivariate Relevance Vector Machines for Tracking. In: Leonardis A., Bischof H., Pinz A. (eds) Computer Vision ECCV 2006. Lecture Notes in Computer Science, vol 3953. Springer, Berlin, Heidelberg

16. Liyang Wei and Robert M. Nishikawa ,'Relevance Vector Machine Learning for Detection of Microcalcifications in Mammograms" IEEE 2005.

17. Qibin Liu, Minlin Yang, Jing Lei, Hongguang Jin, Zhichao Gao, Yalong Wang. Modeling and optimizing parabolic trough solar

18. collector systems using the least squares support vector machine method. Solar Energy, 2012, Vol.86 (7), pp.1973-1980.

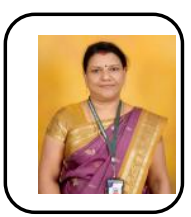

\section{AUTHORS PROFILE}

Mrs., Rekha S.N Completed B-Tech in Electrical and Electronics Engineering from Calicut University and MTech in power systems from Kerala University, also doing $\mathrm{Ph} . \mathrm{D}$. in electrical engineering on Fault diagnosis in Wind Energy Conversion system at, Kalasalingam Academy of Research and Education. Presently Working at Sapthagiri college of engineering Bangalore. She has organized various Conferences, Seminars and conducted many workshops. She has published papers in international journals and Conferences.

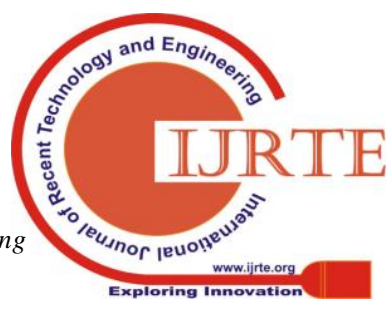




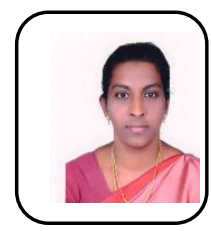

Prof. P. Aruna Jeyanthy Completed B.E in Electrical and Electronics Engineering from Madurai Kamaraj University and M.E in power systems from Annamalai University, also completed Ph.D. in electrical engineering on Evolutionary Algorithm-based Techniques for Voltage Security Enhancement from Anna University. currently works as the Faculty of Electrical and Electronics Engineering, Kalasalingam University. She has organized various Conferences, Seminars and conducted many workshops. She has chaired various technical sessions in many National and International Conferences. She has published papers in 29 international journals and 8 national journals. She has received many number of awards, Prizes and Honors for paper presentations and her valuable services in this field.

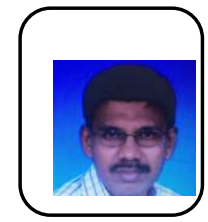

Prof. D. Devaraj Completed B.E and M.E in Electrical \& Electronics Engineering and Power System Engineering in the year 1992 and 1994, respectively, from Thiagarajar College of Engineering, Madurai. From 1994 to 1997, he worked as a Lecturer in Arulmigu Kalasalingam College of Engineering, Krishnankoil. He obtained his Ph.D degree from IIT Madras, Chennai in the year 2001. Since 2001, he is working as a faculty in the Electrical \& Electronics Engineering department of Kalasalingam University. He has organized 6 Conferences, 8 Seminars and conducted 10 workshops. He has published 105 papers in Journals and presented 250 papers in conferences. He has chaired 15 technical sessions in various National and International Conferences. He has Supervised 15 Ph.D, 2 M.S and 25 M.E thesis. Presently, he is guiding 8 Ph.D scholars. His research interest includes Power system security, Voltage stability, Smart grid, Evolutionary algorithms, Neural network and Data Mining. He is a senior member IEEE. Presently, he is the Dean - Academic, Senior Professor/EEE at Kalasalingam University, Krishnankoil 